\title{
The effect of loud noise on the psychological refractory period
}

\author{
PAULA GOOLKASIAN \\ University of North Carolina, Charlotte, North Carolina 28223
}

and

\author{
DAVID C. EDWARDS \\ Iowa State University, Ames, Iowa 50010
}

\begin{abstract}
The psychological refractory period effect was measured under the effects of a loud-noise stressor. It was demonstrated that the loud noise served to exaggerate the delay in the response to the second of two successive stimuli, but the effect was not greater with short interstimulus intervals, as indicated by theory. Arousal appears to affect processing stages prior to response selection.
\end{abstract}

Contemporary theories of information processing have identified a number of mechanisms to explain the effect of arousal on the processing of stimulus information. According to Broadbent's theory $(1958,1971)$, the narrowing of stimulus input that accompanies an increase in arousal involves a filter which selects signals on the basis of common features. Teichner (1968) also uses the concept of a filter, but he places more emphasis on the positive relationship between the rate of processing through the filter and the level of activation. An updating of the theory (Teichner, Note 1) proposed that arousal affects attentional processing through a disruption of the scanning mechanism, a process which deals specifically with the subject's temporal discriminations of successive signals. A third approach presented the allocation mechanism (Kahneman, 1973) as the means through which arousal affects the amount of attention placed on a task. The allocation policy operates flexibly and channels available capacity to appropriate activities. Moderate arousal levels allow for more available capacity than low arousal levels, and states of high arousal bring with them a disruption in the allocation mechanism (Kahneman, 1973).

Within the context of the above theories, it is expected that there are basic changes in processing of stimulus information with variation in arousal level. It is the intent of this investigation to observe the effect of arousal on a person's processing of stimulus information by measuring the effect of a loud-noise stressor on performance in a double-stimulation paradigm. The classic finding with this paradigm is referred to as the psychological refractory period (PRP), and it represents a delay in the response to the second of two signals presented at short interstimulus intervals (ISI). Response conflict theory (Herman \& Kantowitz, 1970) offers the most recent interpretation for the PRP phenomenon. Presenting two successive stimuli at short ISIs (20-200 msec) produces competing response tendencies which delay the response to the second stimulus. If arousal manipulations alter processing as suggested by Broadbent, Kahneman, and Teichner, then the classic attentional paradigm of PRP should be sensitive to the fluctuations of interest.

\section{METHOD}

\section{Task and Apparatus}

The student viewed a 2 by 2 array of signal panels from the window of a semidark sound-resistant booth.

A PRP paradigm was employed in which two successive stimuli, designated in order of presentation $S_{1}$ and $S_{2}$, were presented at varying ISIs, and responses were made to each stimulus, $R_{1}$ and $R_{2}$. Each stimulus was a lighted vertical bar on a Massey-Dickinson electroluminescent panel and appeared for $30 \mathrm{msec}$. There were four panels arranged to the right and left side of a center cross. On each trial there was a $50 \%$ probability that either $S_{1}$ or $S_{2}$ would be displayed on a particular side, and a $33 \%$ probability that the two successive stimuli would appear on the same or alternate sides or that only one stimulus would be presented. Between the presentation of $S_{1}$ and $S_{2}$ there were variable ISIs of $20,50,100$, or $200 \mathrm{msec}$. Random arrangements of ISIs and stimulus locations were programmed on paper tape. Four random orders of 24 trials were used throughout the experiment. There was a constant intertrial interval (ITI) of either 4 or $12 \mathrm{sec}$, and students participated in a block of 120 trials under each of the ITI levels.

To enable the students to indicate a decision regarding the stimulus location, response keys were positioned under the students' left and right index fingers. $R_{1}$ and $R_{2}$ latencies were registered on Hunter Klockounters and recorded by the experimenter.

A precision noise generator supplied continuous white noise through amplifiers to the sound-resistant booth at one of the two noise levels $-50 \mathrm{~dB}$ and $95 \mathrm{~dB}$, measured at the students' head position (weighting $C$ ).

\section{Procedure and Subjects}

Twenty-four volunteer students from a basic psychology class at Iowa State University were randomly assigned to either the loud-noise group or the quiet-noise group. All students had normal vision and hearing, and were offered course credit for their participation.

Initially, both groups participated in a 15 -min practice period 
without noise. The students' task was to indicate the location of the stimulus by pressing the appropriate right or left response key. Each student used both hands to perform the task. The student was instructed to respond to each stimulus as quickly as possible, and he was instructed not to delay $R_{1}$ until $S_{2}$ was displayed.

The experimental session consisted of 240 trials equally distributed over two work periods, separated by a 10-min rest. The experimental conditions differed only in the $\mathrm{dB}$ level of the white noise present in the booth during the experimental session.

\section{Design}

The two noise groups were intended to be medium-and higharousal states. ISIs and ITIs were manipulated as within-subject variables. The presentation order of ISI levels $(20,50,100$, $200 \mathrm{msec}$ ) was random, whereas the two levels of ITI (4 and $12 \mathrm{sec}$ ) were presented in counterbalanced orders between subjects. Different measures representing the first and second halves of the session were also taken.

An ANOVA was performed on the median $R_{1}$ and $R_{2}$ latencies. Interresponse intervals were also noted. IRI $=R_{2}+$ ISI $-R_{1}$ (Kahneman, 1973).

\section{RESULTS AND DISCUSSION}

The PRP, described as a prolonged latency to the $S_{2}$ at short ISIs, is demonstrated in the lower panel of Figure 1 under both noise conditions. The significance of the PRP phenomenon is shown in the main effects of response $[\mathrm{F}(1,20)=176.76, \mathrm{MSe}=.0135, \mathrm{p}<.001]$, ISIs $[\mathrm{F}(3,60)=38.72, \mathrm{MSe}=.0039, \mathrm{p}<.001]$, and their interaction $[\mathrm{F}(1,20)=132.34$, MSe $=.00098$, $\mathrm{p}<.001]$.

The presence of the loud noise tended to lengthen the $R_{2}$ data. Median reaction time to $S_{1}$ was $.456 \mathrm{sec}$ under $55 \mathrm{~dB}$ and $.488 \mathrm{sec}$ under $95 \mathrm{~dB}$; to $S_{2}$ it was $.543 \mathrm{sec}$ under $55 \mathrm{~dB}$ and $.620 \mathrm{sec}$ under $95 \mathrm{~dB}$. It is apparent that, while the loud noise minimally affected the latency to the first signal, it significantly delayed the response to the second $[\mathrm{F}(1,20)=5.76, \mathrm{MSe}=.0035, \mathrm{p}<.02]$.
The effect of loud noise is also seen quite clearly in the IRI data plotted in the top panel of Figure 1. There is a consistently longer IRI at all ISI levels under the presence of loud noise.

According to response conflict theory, the results suggest that the presence of the loud noise served as an added source of distraction which interfered with response selection; however, the interference should diminish with an increase in the ISI. Since the delay in $\mathbf{R}_{\mathbf{2}}$ was not selective to short ISIs, it appears that the loud noise affects processing stages prior to response selection.

Kahneman's (1973) "allocation mechanism" is somewhat supported by the data. The difference in the minimal IRI data across noise levels can be interpreted as support for a larger allocation capacity under quietnoise conditions, but the allocation mechanism is not supported by the slopes of these curves. The slopes of the two IRI curves are approximately the same. If the presence of loud noise affects the allocation of capacity, then there should be some variation in the slope, especially at the short ISI. Small support for Kahneman's theory is observed in the flat function for the first two ISI values, but the IRI curve soon rises with a small positive slope. This rise would not be predicted until at least $400 \mathrm{msec}$ (value of $R_{1}$ ).

The intertrial interval did make a difference in the overall rate of responding $[F(1,20)=11.99, \mathrm{MSe}=.0161$, $\mathrm{p}<.002]$. A 4-sec ITI resulted in shorter median latency than $12 \mathrm{sec}, 509.9$ vs. $541.6 \mathrm{msec}$. It appears that the students had more difficulty keeping track of the time under a long ITI. ITI did not interact with responses $[(F 1,20)<1]$ or noise level $[F(1,20)=3.08$, $\mathrm{p}<.06]$.

First vs. second half of the session was not an influential variable $[\mathrm{F}(1,20)=1.17, \mathrm{p}<.25]$, and it did not interact with any of the variables of interest.

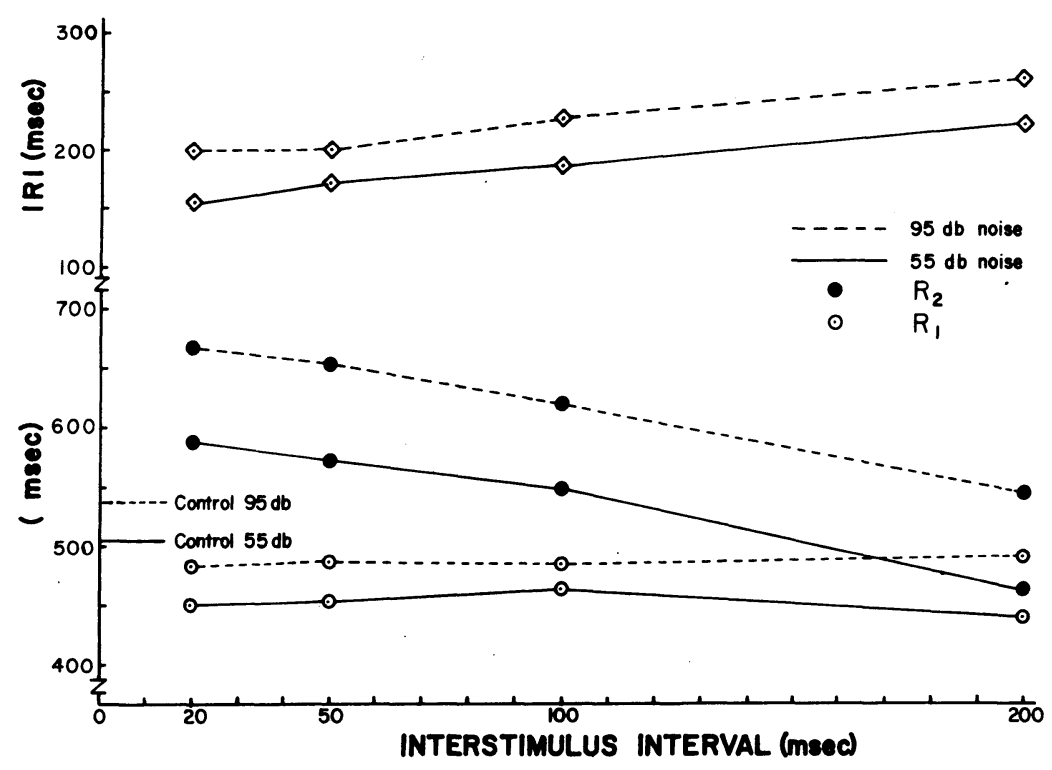

Figure 1. Bottom panel represents the median reaction times, $R_{1}$ and $R_{2}$, across ISI levels under the 55- and 95-dB noise conditions. The top panel plots the interresponse interval data for the two conditions. 
A 2 by 2 ANOVA on the error data (i.e., percent of misses) indicated that the speed-accuracy tradeoff showed little variation across conditions. The longer ITI resulted in slightly more errors than the $4-\sec$ ITI (7\% vs. $5 \%$ ), but the effect was not significant $[\mathrm{F}(1,44)=3.78$, $\mathrm{p}<.10]$. There were no differences across noise levels $[F(1,44)<1]$. Approximately $6 \%$ of the signals were missed under all conditions of the experiment.

From this data, support can be found for the inclusion of arousal as a relevant concept in information processing theories. But, given the variety of theories mentioned in the introduction, the presence of an arousal effect on information processing is not under debate; rather, the questions lie more with the nature of arousal's influence and its position in the processing sequences. The data, although not definitive, suggest that arousal's effect occurs at processing stages prior to response selection. Further work with the PRP, as well as with other classic attentional paradigms, is needed to identify the locus of arousal's effect on information processing.

\section{REFERENCE NOTE}

1. Teichner, W. H. Quantitative models for predicting human visual/perceptual/motor performance. (Technical Report No. 74-3) Las Cruces, New Mexico: New Mexico State University, October 1974.

\section{REFERENCES}

Broadbent, D. E. Percpetion and communication. New York: Pergamon Press, 1958.

Broadbent, D. E. Decision and stress. London: Academic Press, 1971.

Herman, L. M., \& Kantowitz, B. H. The psychological refractory period effect: Only half the double-stimulation story? Psychological Bulletin, 1970, 73, 74-88.

Kahneman, D. Attention and effort. Englewood Cliffs, N.J: Prentice-Hall, 1973.

TeICHNER, W. H. Interactions of behavioral and physiological stress reaction. Psychological Review, 1968, 75, 271-291.

(Received for publication September 24, 1976.) 